\title{
COMMENT
}

DESIGN The Bauhaus: science and a radical arts school p.174
ENVIRONMENTAL HISTORY Life

close to nature beside

the Bering Strait p.176
SUSTAINABILITY Tag research relevant to the Sustainable Development Goals p.178
FORESTRY DOn't forget non-native trees for sequestering carbon $\mathbf{p . 1 7 8}$

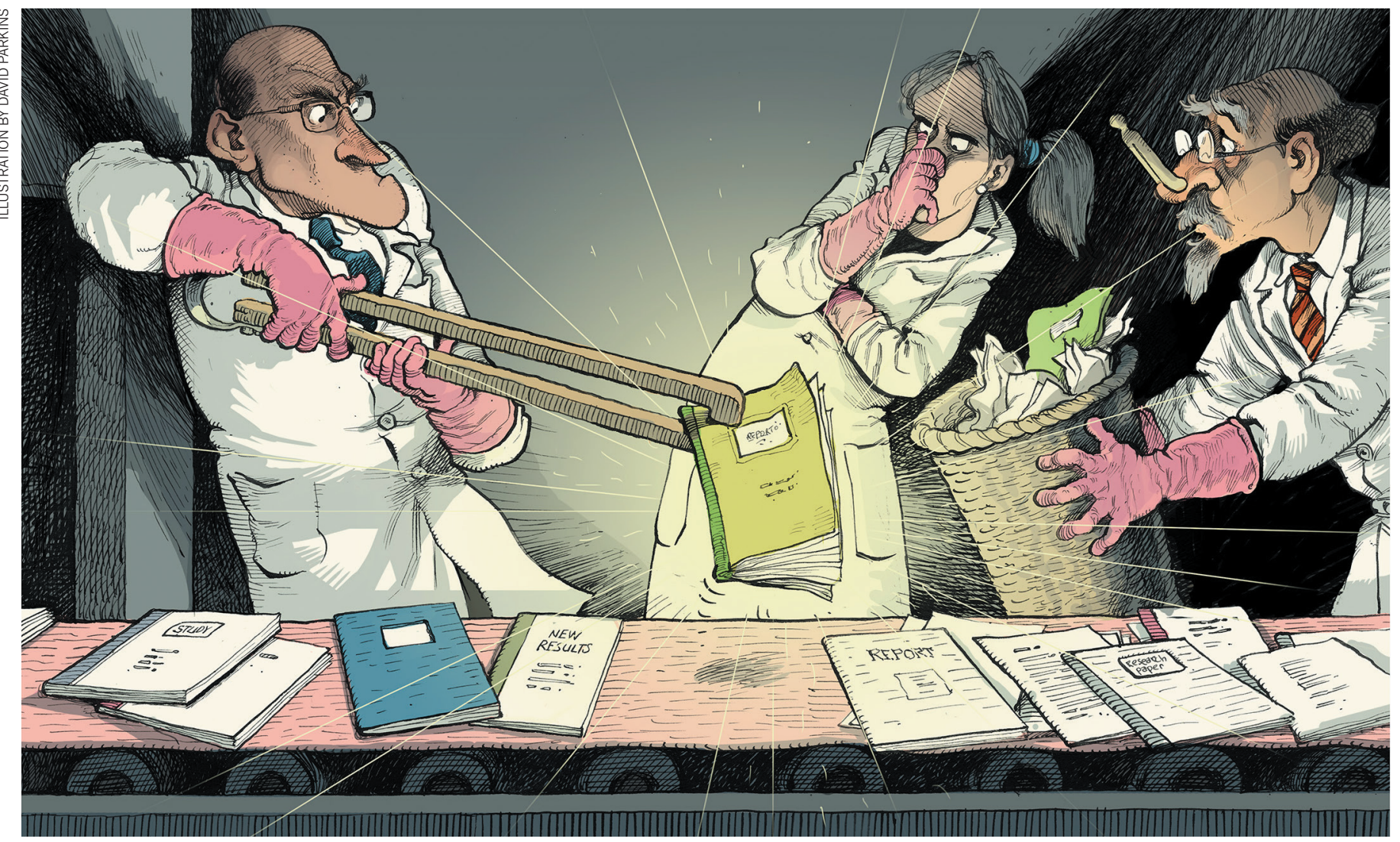

\section{Unethical work must be filtered out or flagged}

Researchers need guidance on how to handle published work whose ethics have been questioned, argue Graeme D. Ruxton and Tom Mulder.

\begin{abstract}
Tn 2014, an article in the Proceedings of the National Academy of Sciences (PNAS) described an experiment investigating whether human emotional states can be transferred to others by "emotional conta-

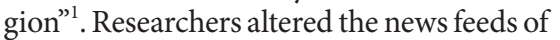
almost 700,000 Facebook users to investigate whether the percentage of positive or negative posts they view affects the tone of those they write. According to Facebook, all users consent to this kind of manipulation when they agree to the company's terms of service.
\end{abstract}

Following widespread debate about the ethics of this research ${ }^{2-4}, P N A S$ issued an editorial expression of concern, noting that the collection of data "may have involved practices that were not fully consistent with the principles of obtaining informed consent and allowing participants to opt out" ${ }^{5}$. Facebook issued an apologetic post ${ }^{6}$.

That social-media data raise challenges that conventional research-ethics frameworks might not be fit for is an area of ongoing debate ${ }^{7}$. Even so, it is concerning to us that, when we read 120 of the more than 1,500 publications citing the PNAS article (according to Google Scholar), we found that only 11 mentioned ethical concerns.

Data-collection protocols routinely go through several rounds of ethical scrutiny by funders, reviewers and journal editors. But if ethically questionable work makes it through these procedures and is published, no formal safeguards are in place to ensure that such research is handled appropriately.

We think that this needs to change. 


\section{WHY NEW GUIDELINES ARE NEEDED}

In our view, the need for clarification on how researchers and others should handle published work that is potentially unethical is increasing for four reasons.

First, as illustrated by the Facebook study, conventional ethics frameworks and guidance keep being outpaced by new technological developments ${ }^{8}$. Second, the number of countries with a strong science base is growing (see go.nature.com $/ 2 \mathrm{jk} 5 \mathrm{cty}$ ), which inevitably leads to greater heterogeneity in cultural norms with respect to research ethics, and to more diversity in the approaches of regulatory authorities.

Third, science is being conducted by a shifting cast of commercial entities either independently from, or in collaboration with, traditional research institutions ${ }^{9}$. Such organizations might not have the same ethics culture and systems of regulation as traditional universities. Also, the involvement of multiple institutions might make it easier for oversight to fall between the cracks. The emotional-contagion research was conducted by Facebook in collaboration with researchers at Cornell University in Ithaca, New York. Cornell's institutional review board apparently decided that the study did not need approval by institutional ethical committees because the data had been collected by an outside agency ${ }^{5}$.

Finally, over the past few decades, awareness of the importance of research ethics has grown. Many studies conducted in respected universities in the twentieth century would never be approved under current legislation - such as the experiments performed in the 1960s by the US social psychologist Stanley Milgram, in which people were tricked into believing that they were giving others potentially lethal electric shocks.

\section{ADDRESSING THE PROBLEM}

So what should be done about ethically problematic published studies, be they presentday ones that would be illegal or unethical, or both, in most places, or historical ones that would now be deemed unethical in many jurisdictions?

We already have ethics committees making judgements about research approaches before publication. It should be possible to implement systems to help filter out, or flag, ethically problematic research after publication. Researchers from different fields, institutions and countries will have different biases and norms when it comes to research ethics. So, ultimately, universal standards are needed, with agreed-on protocols enshrined in scientific codes of practice similar to those laid out in the International Society for Stem Cell Research guidelines.

Retraction Watch, a blog that aims to enhance the transparency of the retraction

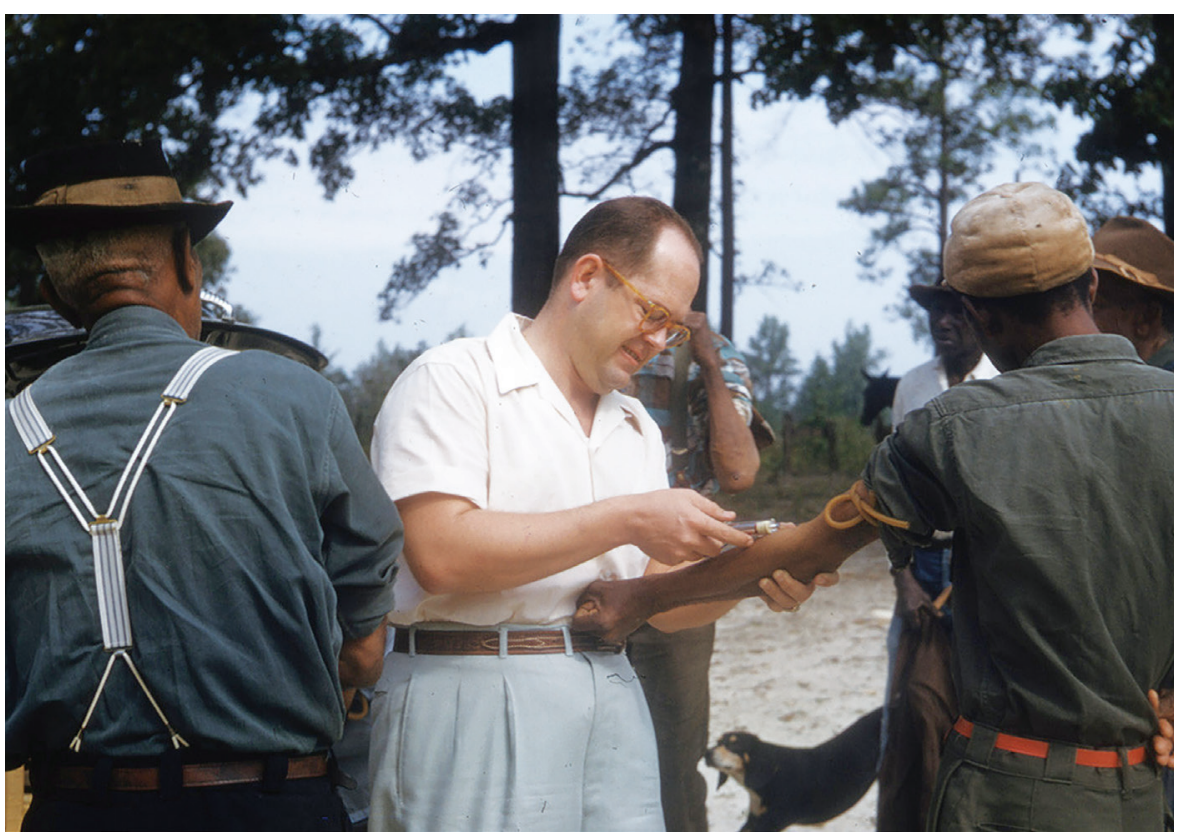

A doctor takes a blood sample during the infamous 'Tuskegee Study of Untreated Syphilis in the African American', which the US government ran between 1932 and 1972.

process, in June announced plans to provide a tool that will allow its users to be alerted to retractions of any papers in their personal libraries. Could something similar one day be used to flag ethically problematic work? Such a tool is needed because not all such work is retracted. Also, it can be years before a study is withdrawn. A Lancet article that claimed to link the MMR vaccination to autism attracted controversy as soon as it was published. It was shown to be fatally flawed, but wasn't retracted until 12 years after publication ${ }^{10}$.

At least in the short term, one possibility is for journal editors to ask authors to confirm - whenever they submit a manuscript - that they have no concerns about the ethics of the methodologies used in any of the publications that they cite. Editors could also ask reviewers to note whether they think that the methodologies used in any of the papers cited in a manuscript might today be criticized on ethical grounds, and perhaps seek further consultation with ethics experts if concerns are raised.

If nothing else, this would help to raise awareness of the issue. And it could help to reduce the number of times researchers cite ethically problematic work without even flagging the potential problem. Rightly or wrongly, the citation of articles is still the main yardstick by which importance and quality in science is measured. So, every citation adds to the perceived quality of an article, and of the associated authors, institutions and journal.

There is no straightforward solution to this problem. Certainly, within medical research, the question of how to handle unethical works has been the subject of heated debate for decades ${ }^{11-13}$. For instance, some argue that citing the notorious experiments carried out by Nazi scientists on concentration-camp inmates legitimizes that research. Others contend that the use of the data and insights from such studies provide a way to honour those who died ${ }^{14}$.

Essentially, we are calling for this discussion to be broadened to include any research that could potentially cause human or animal suffering. Taking steps to address this problem, and making the ethical problems raised by some scientific studies more transparent, will benefit all of science.

Graeme D. Ruxton is professor and Tom Mulder is a student in the School of Biology, University of St Andrews, St Andrews, UK. e-mails: gr41@st-andrews.ac.uk; tom.mulder@hotmail.com

1. Kramer, A. D., Guillory, J. E. \& Hancock, J. T. Proc. Natl Acad. Sci. USA 111, 8788-8790 (2014)

2. Meyer, M. N. Nature 511, 265 (2014).

3. Kleinsman, J. \& Buckley, S. J. Bioeth. Inq. 12 , 179-182 (2015).

4. Jouhki, J., Lauk, E., Penttinen, M., Sormanen, N. \& Uskali, T. Media Commun. 4 (4), 75-85 (2016).

5. Verma, I. M. Proc. Natl Acad. Sci. USA 111, 10779 (2014).

6. Rushe, D. The Guardian (2 October 2014).

7. Golder, S., Ahmed, S., Norman, G. \& Booth, A J. Med. Internet Res. 19, e195 (2017).

8. Caplan, A. L., Parent, B., Shen, M. \& Plunkett, C EMBO Rep. 16, 1421-1426 (2015).

9. Congressional Budget Office. Federal Support for Research and Development (US Congress, 2007).

10. Eggertson, L. Can. Med. Assoc. J. 182, E199-E200 (2010).

11.Paul, C. \& Brookes, B. Am. J. Public Health 105 e12-e19 (2015).

12.Algahtani, H., Bajunaid, M. \& Shirah, B. Neurol. Sci. 39, 829-834 (2018).

13. Tennenhouse, L. Univ. Manitoba J. Med. 1, 6-8 (2018).

14.Mostow, P. J. Law Relig. 10, 403-431 (19931994). 